\title{
Fuzzy Logic Approach for Identifying the Effects of Climate Change on Agricultural Production
}

\author{
Muhammad Shahjalal ${ }^{1}$, Md. Zahidul Alam ${ }^{1}$, Saikh Shahjahan Miah', Abdul Hannan Chowdhury ${ }^{3}$, \\ ${ }^{1}$ Department of Mathematics, Bangamata Sheikh Fojilatunnesa Mujib Science and Technology University, Jamalpur, Bangladesh \\ ${ }^{2}$ Department of Mathematics, Mawlana Bhashani Science and Technology University, Tangail, Bangladesh \\ ${ }^{3}$ School of Business and Economics, North South University, Dhaka, Bangladesh
}

Email address:

hannan.chowdhury@northsouth.edu (A.H. Chowdhury)

*Corresponding author

\section{To cite this article:}

Muhammad Shahjalal, Md. Zahidul Alam, Saikh Shahjahan Miah, Abdul Hannan Chowdhury. Fuzzy Logic Approach for Identifying the Effects of Climate Change on Agricultural Production. International Journal of Agricultural Economics. Vol. 6, No. 4, 2021 , pp. 181-192. doi: $10.11648 /$ j.ijae.20210604.15

Received: July 12, 2021; Accepted: July 26, 2021; Published: August 4, 2021

\begin{abstract}
This study is conducted to measure the effects of climate responsive variables on agricultural production rate in Bangladesh. Agriculture production is affected by the climate changes and natural disasters that cause farmers enormous financial losses. The study focused on the application of fuzzy logic to find out the effect of climate changes on the agricultural production of Bangladesh. The objective of the study is to see the proposed fuzzy system will aid farmers for taking decision of selecting right crop to get the optimal yield. A set of fuzzy rules have been utilized to obtain inference of agriculture production on different linguistic variables. Altered combination of climate variables like temperature, weather disasters, water availability, monsoon level, diseases, species extinction and deforestation are considered as fuzzy linguistic variables generated through sets of different fuzzy rules and applied to estimate agriculture production rate. Findings show that as temperature and weather disaster increases to its highest level the agriculture production reduces to its lowest level. Furthermore, temperature and water availability has a homogeneous effect on agriculture production which indicates that the effects of increased temperature are balanced by the supply of available water. The effects of temperature and monsoon level to agriculture production indicate high precipitation due to monsoon level damages agricultural production. Moderate temperature with pure water availability resulted from moderate monsoon level produces medium agriculture production. It was found that the minimum spread of diseases can produce moderate level of agriculture production. Nonetheless, species extinction has a long term effect on production and deforestation has an immediate effect on agriculture production. In conclusion, climate variables like weather disaster, deforestation, spread of disease, species extinction damage and reduce the agricultural production rate. The study demonstrates the application of fuzzy logic to examine the impact of climate change on the agriculture production in Bangladesh.
\end{abstract}

Keywords: Fuzzy Logic, Fuzzy Expert System, Linguistic Variable, Agriculture Production

\section{Introduction}

Bangladesh is an agro based country where the agricultural sector contributes significantly towards the economic growth of the nation depending on its arable and cultivable land that reduced huge natural and man driven factors. Due to natural disasters and climate factors agriculture production are hampered which causes farmers across the country enormous financial losses. The people who lived in rural and coastal areas in Bangladesh suffer the most from climate driven catastrophes. Hossain and Mojumdar (2018) [3] studied impacts of climate change coastal agricultural, livestock and fisheries sectors which are the main source of livelihood and food security to coastal people. The study found potential impact on agricultural production due to the changes of climate factors.

In the present study effects of some climate variables on agriculture production are reviewed by using a fuzzy logic system. Generally, fuzzy sets are sets whose boundaries are not precisely defined. However, application and pure 
mathematical approaches of fuzzy set theory have been extended after the inception of the theory in 1965 by its founder L. A. Zadeh [1]. Its applications have already been appeared in wide range of areas including information science, decision analysis, medical science, engineering, economics, finance and other disciplines. Growing research is continued on the application fuzzy set theory for developing different framework of fuzzy mathematics including algebra, group theory, topology, statistics, field theory, vector, differential calculus, stochastic process and in other domain of interest. In this study, emphasis will be given on the application of fuzzy logic [2] to examine and measure the effect of climate change variables on the agricultural sector of Bangladesh. The study would apply fuzzy logic system to review impact of climate changes on agriculture production.

\section{Literature Review}

Past records of climate variables like temperature, humidity and rainfall in Bangladesh impacted the high amount of yield that placed the country to the fourth position globally in rice production. Generally, agriculture production depends on factors like seed quality, land and soil types, nitrogen composition, phosphorus and potassium in soil, fertilizer uses to maintain crop nutrients and other climate variables. However, different crops require different types of soil composition and fertilizers. Fuzzy logic system could be used predicting which crop is suitable in a specific area of land and its soil texture. Jawad et al., (2016) [5] proposed a system to analyze the Optimum Crop Cultivation of Bangladesh based on historical average of thirty years rainfall and humidity data on the knowledge of Neuro Fuzzy System (NFS) taking input of humidity, rainfall and temperature to get production output of selective crops namely Aman, Aus, Boro and Potato.

Sannakki \& Rajpurohit (2011) [4] have discussed various image processing techniques, which employ fuzzy techniques and inference rules, and their role in wide range of precision agricultural applications such as feature extraction, texture analysis, agriculture produce grading, effective application of herbicide sprayers in disease control etc. In the proposed system fuzzy logic was applied for image classification and found that decision process obtained from the system performed better.

By taking more climate factors like temperature, humidity, wind, light, precipitation Pandey et. al., (2018) [6] proposed a framework to build an expert system for managing crop crisis. The focus of the system used was different as per the requirement of the modeller and applied to the framework for crop disease diagnostics. The fuzzy expert system (FES) took inputs of temperature, humidity, wind, light, precipitation and generates outputs of crop disease in fuzzy terms (mild, moderate, sever and very sever). Land selection for arable farming required expert knowledge and experience on analysis of "land conditions, climate, soil, topography, water supply, land characteristics and other influential factors." It was observed that in order to identify the land fertility FESs were utilized. Liu et al., (2013) [7] integrated a genetic algorithm with a multi-criteria evaluation based fuzzy inference system (FIS) to construct a self-adapting system that calibrates its evaluation criteria by self-learning from land samples.

Kumar (2011) [8] developed Crop Yield Forecasting models to map relation between climatic data and crop yield. The model was applied for forecasting rice yield by adaptive neuro FIS with time series data. In the system Meteorological terms ("temperature, evaporation, humidity, sunshine hours, rainfall and number of rainfall days") are considered to get the output of rice yield. Identifying the quality of soil, FIS were applied to measure quality of crops, produced food and fruits by taking inputs of different quality variables. Alavi (2013) [9] applied Mamdani FIS (MFIS) for decision making technique to classify the Mozafati dates based on quality. The proposed system took inputs of date length and freshness for determining the quality of dates.

Management of soil, crop, water, pest/disease and waste are needed to take care of farming. To make farming sustainable the components of environmental or natural health, financial or economic profitability, social aspect of equity and other physical aspects are required to maintain. Rajaram and Das (2010) [11] proposed a fuzzy rule based approach to model the interactions of sustainability components in an agro-ecosystem which is explained a typical agrarian village in southern India. Liu et al., (2009) [12] utilized fuzzy logic as a decision support approach for environmental impact assessment (EIA). The system takes inputs (air, water, soil, noise, solid waste, terrestrial, aquatic, economics, society and culture) and evaluates "environmental impacts" in the construction projects of "Taiwan High-Speed Rail."

Expert system in agriculture helps farmers in many dimensions for farming success. Based on viability of expert system different types of FES are developed in agriculture sector. Yelapure and Kulkarni (2012) [13] explained needs of expert system in agriculture and reviewed various expert systems in agriculture. Dubey et al., (2013) [14] presents a review of various FESs in agriculture over the last two decades. Guillaume et. al., (2012) [15] applied FisPro to discusses the originality of FIS and their capability for the integration expertise and rule learning from data into a single framework, analysing their place relatively to concurrent approaches. Karthika et. al., (2018) [10] studied to frame the FES to examine the impact of climate change in the Indian Agriculture. The system takes input of six variables and infers the annual percentage of agricultural product. Zhang and Cai (2011) [16] studied the impact of climate change on worldwide agricultural land availability, considering uncertainty in climate change projections and ambiguity with regard to land classification. The study found that the total global arable land area is likely to decrease by $0.8-1.7 \%$ and increase by $2.0-4.4 \%$ under a given scenario.

In the present study fuzzy mathematical approach are reviewed to predict agriculture production which is implied by the effects of climate variables such as temperature, weather disasters, monsoon level, water availability, species 
extinction, spread of diseases and deforestation. The study have applied Fispro version 3.7 an open source software and fuzzy TECH 8.77 e to generate fuzzy rules, figures and outputs of the study.

\section{Theoretical Background}

The section defines some definitions and terms on fuzzy sets and fuzzy logic which are related to the study. For details on fundamentals of fuzzy sets and system we refer readers to $[17,18]$.

Definition 3.1. [17] Let $\mathrm{X}$ be a non-empty set and $\mathrm{I}=[0,1]$ be a unit interval. By fuzzy set on $\mathrm{X}$ we mean a membership function

$$
\mu(\mathrm{x}): \mathrm{X} \rightarrow \mathrm{I}, \mathrm{I} \mapsto \mu(\mathrm{x})
$$

where $\mu(x)$ is interpreted as the grade of membership of $\mathrm{x} \in \mathrm{X}$ under $\mu$.

Simply, any function $\mathrm{A}: \mathrm{X} \rightarrow \mathrm{I}$ is called a Fuzzy set where $\mathrm{X}$ is referential set and $\mathrm{I}=[0,1]$ is valuation set.

Set of all fuzzy sets on $\mathrm{X}$ is denoted by $\mathrm{I}^{\mathrm{X}}$ and $\mathrm{A} \subset \mathrm{I}^{\mathrm{X}}$. Membership function of a fuzzy set is normally denoted by $\mu_{\mathrm{A}}(\mathrm{x})$ or simply $(\mathrm{x})$.

Definition 3.2. [19] Let $A \subset I^{X}$ be a fuzzy set the support of $\mathrm{A}$ is the set of all points $\mathrm{X}$ in $\mathrm{X}$ defined by

$$
\operatorname{support}(A)=\{x \in X \mid A(x)>0\} \text {. }
$$

Definition 3.3. [19] Crossover points of a fuzzy set $A \subset I^{X}$ is a point $\mathrm{x} \in \mathrm{X}$ at which $\mathrm{A}(\mathrm{x})=0.5$; is defined by

$$
\operatorname{crossover}(A)=\{x \in X \mid A(x)=0.5\} \text {. }
$$

Definition 3.4. [19] Let $\mu_{\mathrm{A}}(\mathrm{x})$ or $\mathrm{A}(\mathrm{x})$ be a triangular membership function of a fuzzy set $\in \mathrm{I}^{\mathrm{X}}$. The membership function is defined

$$
A(x)=\operatorname{triangle}(x ; a, b, c)=\left\{\begin{array}{cc}
0 & c \leq x \leq a \\
\frac{x-a}{b-a} & a \leq x \leq b \\
\frac{c-x}{c-b} & b \leq x \leq c
\end{array}\right.
$$

Definition 3.5 [19] Let $\mathrm{A}(\mathrm{x})$ and $\mathrm{B}(\mathrm{x})$ be two membership functions of fuzzy sets $A, B \in I^{X}$. The union or max operation on these functions is a function $C(x)$ which is defined by

$$
\mathrm{C}(\mathrm{x})=\mu_{\mathrm{A \cup B}}(\mathrm{x})=\max (\mathrm{A}(\mathrm{x}), \mathrm{B}(\mathrm{x})) .
$$

Definition 3.6. [19] Let $A(x)$ and $B(x)$ be two membership functions of fuzzy sets $A, B \in I^{X}$. The intersection or min operation on these functions is a function $\mathrm{C}(\mathrm{x})$ which is defined by

$$
\mathrm{C}(\mathrm{x})=\mu_{\mathrm{A} \cap \mathrm{B}}(\mathrm{x})=\min (\mathrm{A}(\mathrm{x}), \mathrm{B}(\mathrm{x})) .
$$

Definition 3.7. [19] Let $A \in I^{X}$ and $B \in I^{Y}$ be two fuzzy sets. A fuzzy relation $\mathrm{R}$ from $\mathrm{A}$ to $\mathrm{B}$ is defined by

$\mathrm{R}: \mathrm{A} \times \mathrm{B} \rightarrow \mathrm{I}$, where $\mathrm{I}=[0,1]$ is unit interval. Set of all fuzzy relations from $A$ to $B$ is denoted by $I^{A \times B}$.
Definition 3.8. [19] Let $\in \mathrm{I}^{\mathrm{X}}, \mathrm{B} \in \mathrm{I}^{\mathrm{Y}}$, and $\mathrm{C} \in \mathrm{I}^{\mathrm{Z}}$ be three fuzzy sets. If $R_{1}$ and $R_{2}$ are two fuzzy relations defined from $A \times B$ and $B \times C$ respectively. The "max-min" composition of $R_{1}$ and $R_{2}$ is also a fuzzy set defined by

$$
\begin{aligned}
& \mathrm{R}_{1} \circ \mathrm{R}_{2}=\left\{(\mathrm{x}, \mathrm{z}) ; \max \left(\min \left(\mathrm{R}_{1}(\mathrm{x}, \mathrm{y}), \mathrm{R}_{2}(\mathrm{y}, \mathrm{z})\right)\right) \mid \mathrm{x} \in \mathrm{X}, \mathrm{y} \in\right. \\
& \mathrm{Y}, \mathrm{z} \in \mathrm{Z}\} \text {. }
\end{aligned}
$$

Definition 3.9. [19] Linguistic variable is characterized by a quintuple $(x, T(x), X, G, M)$ in which $x$ is the name of the variable; $T(x)$ is the "term set", of $x$-that is, the set of its linguistic values, or linguistic terms; $X$ is the universe of discourse, $G$ is a "syntactic rule" which generates the terms in $\mathrm{T}(\mathrm{x})$; and $\mathrm{M}$ is a "semantic rule" which associates with each linguistic value $A$ its meaning $M(A)$, where $M(A)$ denotes fuzzy set in $\mathrm{X}$.

\section{Fuzzy Rule Based Systems}

Fuzzy rule-based systems (FRBS) are based on the fuzzy concept proposed by Zadeh in 1965 [1], which represents the reasoning of human experts in construction rules (set of IF-THEN- statements) to handle real-life problems such as control, prediction and inference, data mining, bioinformatics data processing, robotics and speech recognition. FRBS are also known as FISs, fuzzy logic based system, fuzzy compositional rule of inference, fuzzy controllers and fuzzy models. One of the important uses of FRBS is to work with imprecise information. A fuzzy rule based systems (FRBS) is the process of obtaining a conclusion form a set of given inputs. The basic rule (law) for FRBS is the compositional rule of inference.

Definition 4.1. [20] A fuzzy rule is defined as a triplet (A; $\mathrm{B}$; R) defined by: $\mathrm{A} \times \mathrm{B} \rightarrow \mathrm{I}$, where $\mathrm{A} \in \mathrm{I}^{\mathrm{X}} ; \mathrm{B} \in \mathrm{I}^{\mathrm{Y}}$, linked through a fuzzy relation $\mathrm{R} \subset \mathrm{I}^{\mathrm{X} \times \mathrm{Y}}$.

Definition 4.2. [20] Mamdani fuzzy rule of "If $x$ is $A$ then $\mathrm{y}$ is $\mathrm{B}$ " is defined as a fuzzy relation as follows:

$$
\mu_{\mathrm{R}}(\mathrm{x}, \mathrm{y})=\mathrm{A}(\mathrm{x}) \wedge \mathrm{B}(\mathrm{y})
$$

Where the inference is obtained by

$$
\mu_{\mathrm{B}}(\mathrm{y})=\max \left(\min \left(\mu_{\mathrm{A}}(\mathrm{x}), \mu_{\mathrm{R}}(\mathrm{x}, \mathrm{y})\right)\right)
$$

\subsection{Fuzzy Inference System the If-then Rules}

FIS is the process of obtaining a conclusion or decision from given set of ambiguous inputs. The basic rule of FIS is the compositional rule of inference [20,21]. A single fuzzy relation is not sufficient to make a decision. Applications require a finite collection of statements that can be expressed in terms of fuzzy logics or rules. The collection of rules is called a rule block.

Definition 4.3. [20] Fuzzy rules of inference for a single ambiguous input is in the form of "If $x$ is $A_{i}$ then $y$ is $B_{i} ; i=$ $1, \ldots, n$ ", is defined by the fuzzy relation by

$$
\mathrm{R}(\mathrm{x}, \mathrm{y})=\mathrm{V}_{\mathrm{i}=1}^{\mathrm{n}}\left(\mathrm{A}_{\mathrm{i}}(\mathrm{x}) \wedge \mathrm{B}_{\mathrm{i}}(\mathrm{y})\right)
$$

To construct a FIS many rules are required to meet the 
objective. Suppose $A_{i} \in I^{X} ; B_{i} \in I^{Y}$ and $C_{i} \in I^{Z} ; i=1, \ldots, n$; are fuzzy sets. A fuzzy rule based inference system constructed two ambiguous inputs are as expressed by "if ( $\mathrm{x}$ is $\left.A_{i}\right)$ and $\left(y\right.$ is $\left.B_{i}\right)$ then $z$ is $C_{i}$ ". For example, FIS consisting of two inputs is shown Table 1 .

Table 1. Generalized FIS.

\begin{tabular}{|c|c|c|c|c|}
\hline Antecedent & $:$ & & $\mathbf{x} \in \mathbf{A}_{\mathbf{i}}$ and $\mathbf{x}$ & $E \mathbf{B}_{\mathrm{i}}$ \\
\hline Rule 1 & : & If $x \in A_{1}$ & and $\mathrm{y} \in \mathrm{B}_{1}$ & then $\mathrm{z} \in \mathrm{C}_{1}$ \\
\hline $\begin{array}{l}\text { Rule } 2 \\
\text { : }\end{array}$ & $\begin{array}{l}: \\
:\end{array}$ & If $x \in A_{2}$ & $\begin{array}{l}\text { and } y \in B_{2} \\
:\end{array}$ & then $\mathrm{z} \in \mathrm{C}_{2}$ \\
\hline $\begin{array}{l}\text { Rule } \mathrm{n} \\
\text { Conclusion }\end{array}$ & : & If $x \in A_{n}$ & $\begin{array}{l}\text { and } \mathrm{y} \in \mathrm{B}_{\mathrm{n}} \\
\mathrm{z} \in \mathrm{C}_{\mathrm{i}}\end{array}$ & then $\mathrm{z} \in \mathrm{C}_{\mathrm{n}}$ \\
\hline
\end{tabular}

The process of conflict resolution [22] is applied to decide which consequence has taken place.

\subsection{Operational Overview of Fuzzy Inference}

If $\mathrm{A}$ and $\mathrm{B}$ are the antecedent the inputs in a FIS, then firing strength of $i$-th rule is denoted by $\alpha_{i}$ and the $i$-th rule is calculated by $\alpha_{i}=A_{i}(x) \wedge B_{i}(y)$. The inference obtained from the $i$-th rule or logic is given by $C_{i}^{\prime}(z)=\alpha_{i} \wedge C_{i}(z)$.

The final result is obtained by aggregating the inferred result from n-rules. The aggregating result can be found by

$$
\mathrm{C}_{\mathrm{i}}(\mathrm{Z})=\left[\alpha_{1} \wedge \mathrm{C}_{1}(\mathrm{Z})\right] \vee\left[\alpha_{2} \wedge \mathrm{C}_{2}(\mathrm{Z})\right] \vee \cdots \vee\left[\alpha_{\mathrm{n}} \wedge \mathrm{C}_{\mathrm{n}}(\mathrm{Z})\right]
$$

Operational overview of FIS is shown in Table 2.

Table 2. Generalized FIS operational overview.

\begin{tabular}{lll}
\hline $\begin{array}{l}\text { Antecedent } \\
\text { (Facts) }\end{array}$ & $\min \left(\mathbf{x} \in \mathbf{A}_{\mathbf{i}}, \mathbf{y} \in \mathrm{B}_{\mathrm{i}}\right) \rightarrow \mathrm{z} \in \mathbf{C}_{\mathbf{i}}$ & Output $\mathrm{z} \in \mathbf{C}_{\mathbf{i}}$ \\
\hline Rule 1 & $\mathrm{x} \in \mathrm{A}_{1}$ and $\mathrm{y} \in \mathrm{B}_{1}$ then $\mathrm{z} \in \mathrm{C}_{1}$ & $\mathrm{z}_{1}=\min \left(\min \left(\mathrm{A}_{1}, \mathrm{~B}_{1}\right), \mathrm{C}_{1}\right)$ \\
Rule 2 & $\mathrm{x} \in \mathrm{A}_{2}$ and $\mathrm{y} \in \mathrm{B}_{2}$ then $\mathrm{z} \in \mathrm{C}_{2}$ & $\mathrm{z}_{2}=\min \left(\min \left(\mathrm{A}_{2}, \mathrm{~B}_{2}\right), \mathrm{C}_{2}\right)$ \\
$:$ & $:$ & $:$ \\
Rule $\mathrm{i}$ & $\mathrm{x} \in \mathrm{A}_{\mathrm{i}}$ and $\mathrm{y} \in \mathrm{B}_{\mathrm{i}}$ then $\mathrm{z} \in \mathrm{C}_{\mathrm{i}}$ & $\mathrm{z}_{2}=\min \left(\min \left(\mathrm{A}_{\mathrm{i}}, \mathrm{B}_{\mathrm{i}}\right), \mathrm{C}_{\mathrm{i}}\right)$ \\
$:$ & $:$ & $:$ \\
Rule $\mathrm{n}$ & $\mathrm{x} \in \mathrm{A}_{\mathrm{n}}$ and $\mathrm{y} \in \mathrm{B}_{\mathrm{n}}$ then $\mathrm{z} \in \mathrm{C}_{\mathrm{n}}$ & $\mathrm{z}_{\mathrm{n}}=\min \left(\min \left(\mathrm{A}_{\mathrm{n}}, \mathrm{B}_{\mathrm{n}}\right), \mathrm{C}_{\mathrm{n}}\right)$ \\
Conclusion & $\min \left(\mathrm{x} \in \mathrm{A}_{\mathrm{i}}, \mathrm{y} \in \mathrm{B}_{\mathrm{i}}\right) \rightarrow \mathrm{z} \in \mathrm{C}_{\mathrm{i}}$ & $\mathrm{z}=\max \left(\mathrm{z}_{1}, \mathrm{z}_{2}, \ldots, \mathrm{z}_{\mathrm{n}}\right)$ \\
\hline
\end{tabular}

\section{Climate Change and Exposure}

Earth's atmosphere naturally present gases $\mathrm{C}_{2} \mathrm{O}$ (Carbon dioxide), $\mathrm{H}_{2} \mathrm{O}$ (Water vapour), $\mathrm{CH}_{4}$ (Methane), $\mathrm{N}_{2} \mathrm{O}$ (nitrous oxides), $\mathrm{O}_{3}$ (Ozone), CFCs (Chlorofluorocarbons) and some other gases absorb Infrared (IR) light radiation and re-emit in all directions that results in warm atmosphere and consequently the surface air temperature of the planet is increasing [23]. This mechanism causes global warming contributing to climate change with the effects of melting ice caps, rising sea level, changing temperature, rainfall, flood, cyclone, storm surge, water and soil salinity, land erosion, siltation, drought, diseases and more. These changes impact on agriculture production due to deteriorating land, ailing plants, and declining soil fertility. The study limited to agriculture production for climate change that has impacts of monsoon level, weather disaster, pure water availability, species extinction, spread of diseases and deforestation [10]. The significant effects of climate change on rice production and food security reported in [24].

\subsection{Temperature (Temp)}

Increases in temperature changes in perception patterns, causes weather changes and reduces water availability that results in extreme impact of agricultural productivity. Increase in annual rainfall and long-term temperature significantly enhance production and variability in temperature and long-term temperature reduce efficiency of production [25]. Increase in temperature create heat waves which is harmful for all kind of lives and the temperature has impacts on agriculture, water supplies, human health, animals, plants, forests and ecosystems [26]. Global yields of major crops have been found to increases and decreases due to temperature [27]. Various effect of temperature change are found in [28] and it was found that event of heavy rainfall have been observed due to 2 degrees Celsius rise in temperature. Historical effects of temperature fluctuations and economic growth discussed in [29] and it was found that "temperature rise by 1 degree Celsius in a given year reduces economic growth on the average by $1.3 \%$."

\subsection{Weather Disasters (WD)}

Bangladesh is in seventh position among countries of the most vulnerable to extreme weather conditions and in the third most of events occurred by the natural disasters. According to "World Risk Index 2016" Bangladesh is the world's fifth most exposed country to natural disasters [30]. Flood and water logging in coastal area are mostly happened events. Coastal areas are the most vulnerable prone reason for "Ingression of Soil Salinity, Flood and Water Logging and Salinity and Water Logging" in Bangladesh [31]. Weather disaster damages the wealth and agriculture production. Hence, increase number of events in weather disaster reduced to agriculture production.

\subsection{Monsoon Level (ML)}

Monsoon climate in Bangladesh is characterized by three distinct seasons like a hot, humid summer from March to June; a cool, rainy season from June to October; and a cool, dry winter from October to March. Monsoon level is a source of water resource and is indexed by rainfall level in millimeter. Historical monsoon level with maximum and minimum rainfall is studied in [32] and observed that increasing trend of rainfall in monsoon and post-monsoon seasons while a decreasing trend was found in pre-monsoon and winter season.

\subsection{Water Availability (WA)}

Agriculture production requires certain amount of water to produce crops, livestock, fisheries, processing foods and products. Water being an essential element has significant impact on agriculture but climate change reduces water availability in areas where irrigation is the most required factors of growing crops. Role of soil water availability was studied in [33] for producing rice in different districts in Bangladesh. Findings show that regional ground water level declines due to irrigation in agriculture [34]. 


\subsection{Species Extinction (SE)}

Climate change over the past 30 years has produced numerous shifts in the distribution and abundance of species worldwide. Climate change has already produced shifts in the distribution of some species, such as amphibians, grasses, migratory birds and butterflies. Species extinction and shifts for survival occurred due to increases in yearly temperature [35].

\subsection{Spread of Diseases (SD)}

Climate change causing migration of habitats, travel away, and disease transmission pattern are consequence of spreading diseases [36]. Transmission and spreading diseases impact on market access and agricultural production. Diseases include micro-organisms, disease agents (bacteria, fungi and viruses), infectious agents, parasites and genetic disorders.

\subsection{Deforestation (DF)}

Over the last few decade forests in Bangladesh have been declined significantly in terms of area and quality. The annual deforestation rate is estimated to be around 3.3\%. However, deforestation decreases in soil quality [37].

\subsection{Problem Descriptions}

Bangladesh is a country with distinct agricultural and rural significance. It is the 93rd largest country by area and the 8th most populated country in the world [5]. Economy of Bangladesh is primarily dependent on agriculture and this sector shares about $14.23 \%$ of Gross Domestic Product (GDP) at constant price and it absorbs $41 \%$ of the labor force [38]. Generally agriculture covers crops, livestock, fishery, environment, forestry, and etc. Crop cultivation was a major part of Bangladesh's GDP [5,39] till 2010 but after that it has dropped by $18 \%$ which indicates that the sector needs more attention on finding the causes, facts and factors support to regain its healthy position in the GDP. To support huge population of Bangladesh, the country needs high volume of agro-products and crops to meet its demand. The adverse change in the climate leads to an impact on the agriculture to a greater extent. For instance, the increases or decreases in temperatures, reduction of water may results to less yield of agriculture. Hossain et al., (2020) [40] assess the effects of climate change on farmland value in Bangladesh and observed that farmland values of farmers are sensitive to climate change. In this study, the main focus is to measure and review the impact of climate change on Agriculture in Bangladesh using fuzzy rule system applied in [10].

Since the agro sector contributes the most in the GDP of Bangladesh and the country heavily depends on its arable and cultivable land, however that suffers the most from climate driven catastrophes. Agriculture productions are hampered and farmers across the country encountered enormous financial losses. The present study is therefore very vital to figure out potential factors that impacts agricultural production due to climate changes. In the present study effects of some climate variables on agriculture production are reviewed by using a fuzzy logic system. The study would emphasis on the application of fuzzy logic [2] to examine and measure the effect of climate change variables on the agricultural sector of Bangladesh.

\section{Fuzzy Expert System Structure}

The proposed expert system infer agriculture product which is responsive to climate changes. The system structure identifies the fuzzy logic inference flow from a set of input variables to the output variables. The fuzzification in the input interfaces translates real value of inputs into fuzzy values in $[0,1]$. The FIS takes place in rule blocks which contain the linguistic control rules. The outputs of these rule blocks are linguistic variables. The defuzzification in the output interfaces translates them into real or analog variables.

\subsection{Input and Output Variables}

Agriculture yield depends on many weather and environment related variables. The present study considered variables like temperature, weather disasters, water availability, monsoon level, spread of diseases and species extinction. In the fuzzy logic system all input and output variables are linguistic variables represented by linguistic terms of membership function.

\subsubsection{Linguistic Variables Determination}

All linguistic variables of the study are defined by 5 linguistic terms consisting with 5 triangular membership functions namely very low (vl), low (l), medium (m), high (h) and very high (vh).

Let $A$ be a linguistic variable and $\mathrm{x}_{\mathrm{i}} \in \mathrm{X} \subset \mathrm{R}^{+}$, $\mathrm{i}=1,2, \ldots, \mathrm{n}$ are real numbers. Then, the linguistic variable $\mathrm{A}$ under 5 terms corresponding to 5 membership functions is defined by

$$
\text { A: }\left(\mu_{\mathrm{x}_{1}}, \mu_{\mathrm{x}_{2}}, \mu_{\mathrm{x}_{3}}, \mu_{\mathrm{x}_{4}}, \mu_{\mathrm{x}_{5}} \mid \mathrm{x} \in \mathrm{X} \subset \mathrm{R}^{+}\right) \rightarrow[0,1]
$$

or simply variable $\mathrm{A}$ is expressed by

$$
\mathrm{A}\left(\mu_{\mathrm{x}_{1}}, \mu_{\mathrm{x}_{2}}, \mu_{\mathrm{x}_{3}}, \mu_{\mathrm{x}_{4}}, \mu_{\mathrm{x}_{5}} \mid \mathrm{x}_{\mathrm{i}} \in \mathrm{X} \subset \mathrm{R}^{+} ; \mathrm{i}=1, \cdots, 5\right) \text {. }
$$

Note that Linguistic variable takes input of real number from the discussed domain and returns value(s) of membership grades. The diagrams of the Linguistic variables of FES are shown in Figures 1-8.

Figure 1 depicts linguistic variable (Temp) is defined by $\operatorname{Temp}\left(\mu_{\mathrm{vl}}, \mu_{1}, \mu_{\mathrm{m}}, \mu_{\mathrm{h}}, \mu_{\mathrm{vh}} \mid\right.$ inputs $\left.\in[5,35]\right)$.

Figure 2 depicts linguistic variable WD is defined by $\mathrm{WD}\left(\mu_{\mathrm{vl}}, \mu_{\mathrm{l}}, \mu_{\mathrm{m}}, \mu_{\mathrm{h}}, \mu_{\mathrm{vh}} \mid\right.$ inputs $\left.\in[20,50]\right)$.

Figure 3 depicts linguistic variable WA is defined by $\mathrm{WA}\left(\mu_{\mathrm{vl}}, \mu_{1}, \mu_{\mathrm{m}}, \mu_{\mathrm{h}}, \mu_{\mathrm{vh}} \mid\right.$ inputs $\left.\in[2,7]\right)$.

Figure 4 depicts linguistic variable ML is defined by $\operatorname{ML}\left(\mu_{\mathrm{vl}}, \mu_{\mathrm{l}}, \mu_{\mathrm{m}}, \mu_{\mathrm{h}}, \mu_{\mathrm{vh}} \mid\right.$ inputs $\left.\in[200,1800]\right)$. 


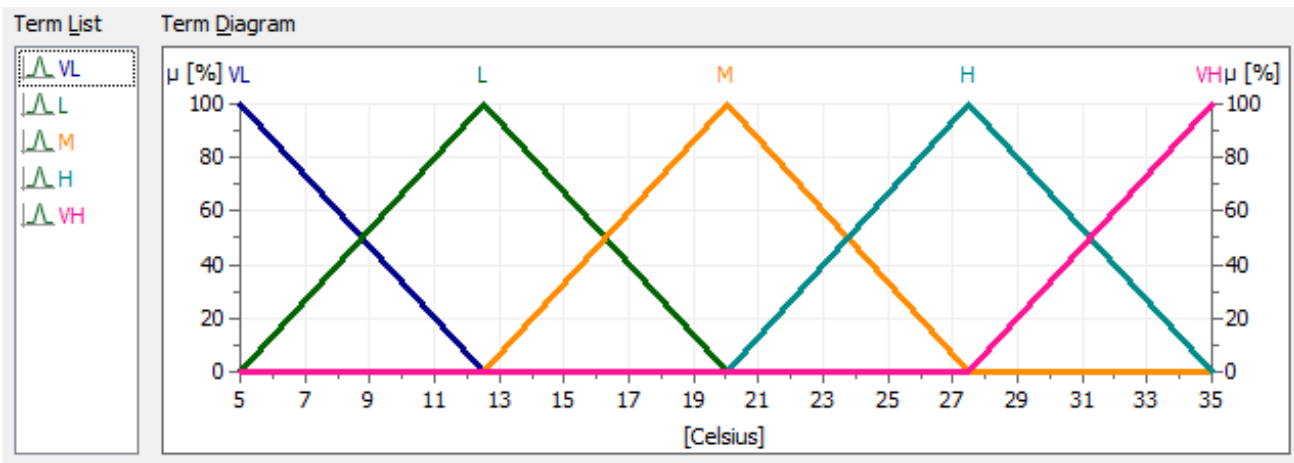

Figure 1. Linguistic Variable Temperature.

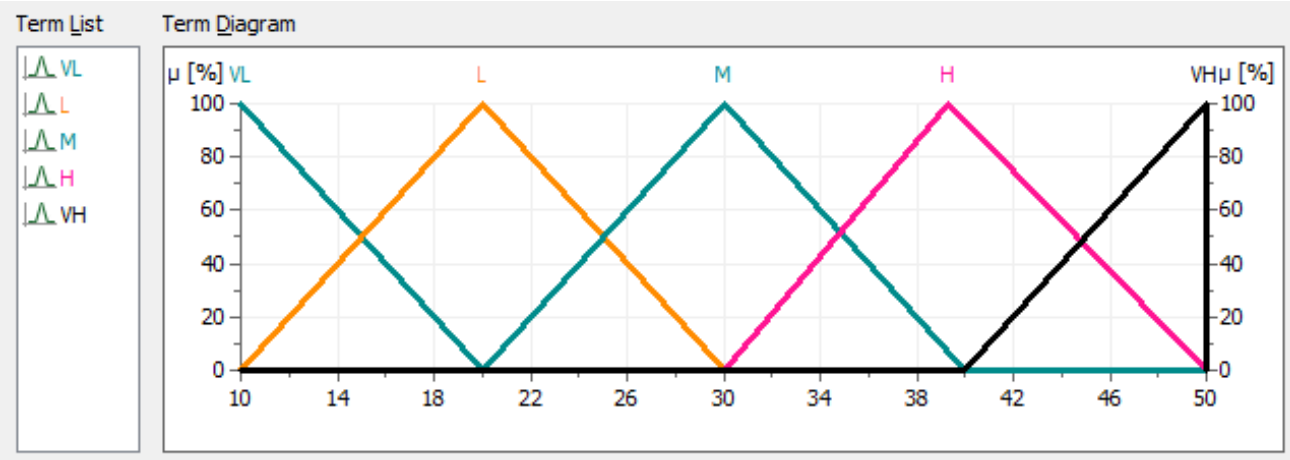

Figure 2. Linguistic Variable Weather Disasters.

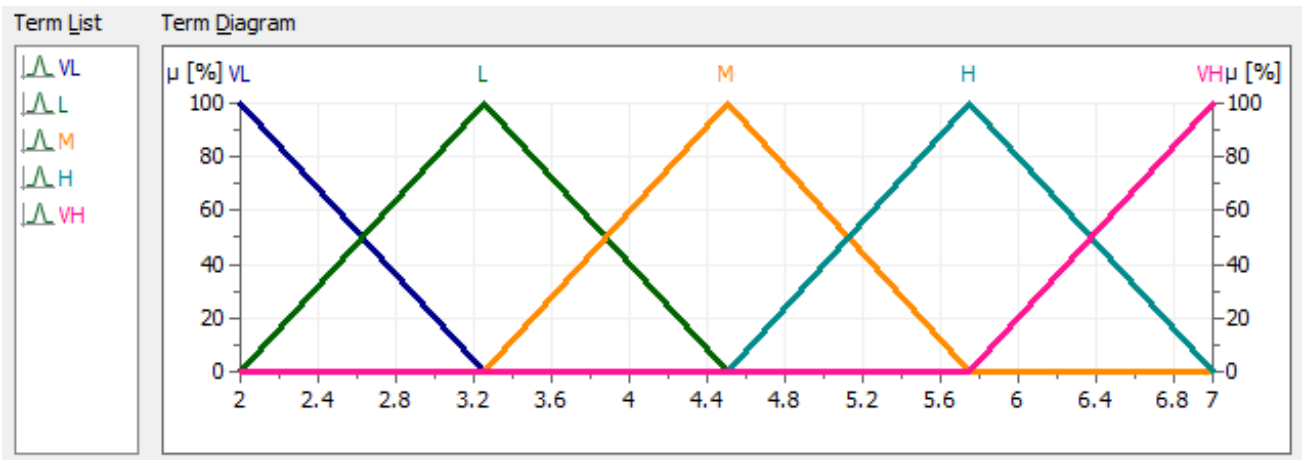

Figure 3. Linguistic Variable Water Availability.

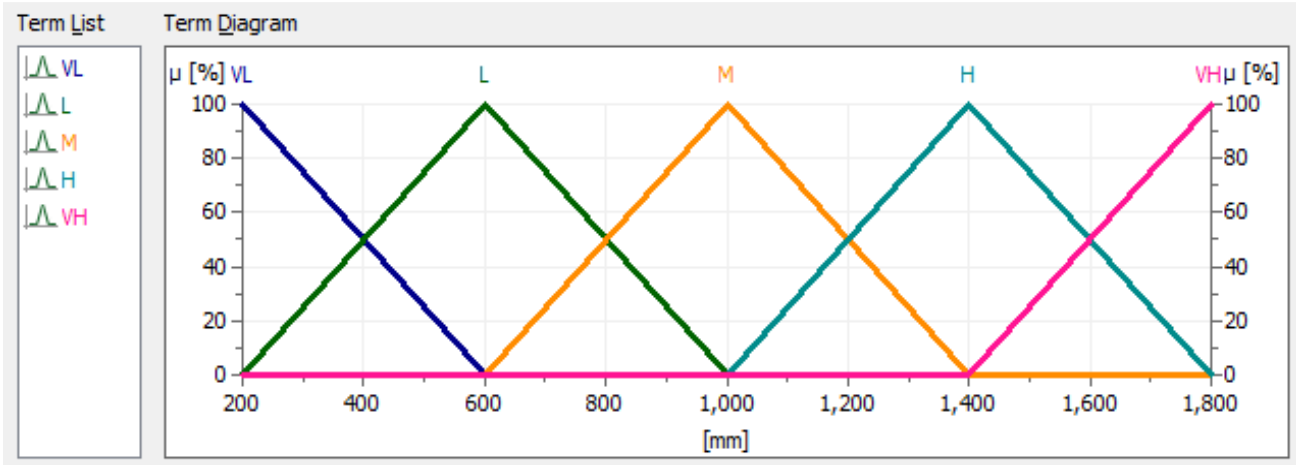

Figure 4. Linguistic Variable Monsoon Level.

Figure 5 depicts linguistic variable $\mathrm{SE}$ is defined by $\mathrm{SE}\left(\mu_{\mathrm{vl}}, \mu_{\mathrm{l}}, \mu_{\mathrm{m}}, \mu_{\mathrm{h}}, \mu_{\mathrm{vh}} \mid\right.$ inputs $\left.\in[1.4,6]\right)$.

Figure 6 depicts linguistic variable $S D$ is defined by $\operatorname{SD}\left(\mu_{\mathrm{vl}}, \mu_{1}, \mu_{\mathrm{m}}, \mu_{\mathrm{h}}, \mu_{\mathrm{vh}} \mid\right.$ inputs $\left.\in[10,25]\right)$.

Figure 7 depicts linguistic variable DF is defined by $\operatorname{DF}\left(\mu_{\mathrm{vl}}, \mu_{\mathrm{l}}, \mu_{\mathrm{m}}, \mu_{\mathrm{h}}, \mu_{\mathrm{vh}} \mid\right.$ inputs $\left.\in[0,5]\right)$.

Figure 8 depicts Linguistic variable AP is defined by $\operatorname{AP}\left(\mu_{\mathrm{vl}}, \mu_{1}, \mu_{\mathrm{m}}, \mu_{\mathrm{h}}, \mu_{\mathrm{vh}} \mid\right.$ inputs $\left.\in[0,1]\right)$. 


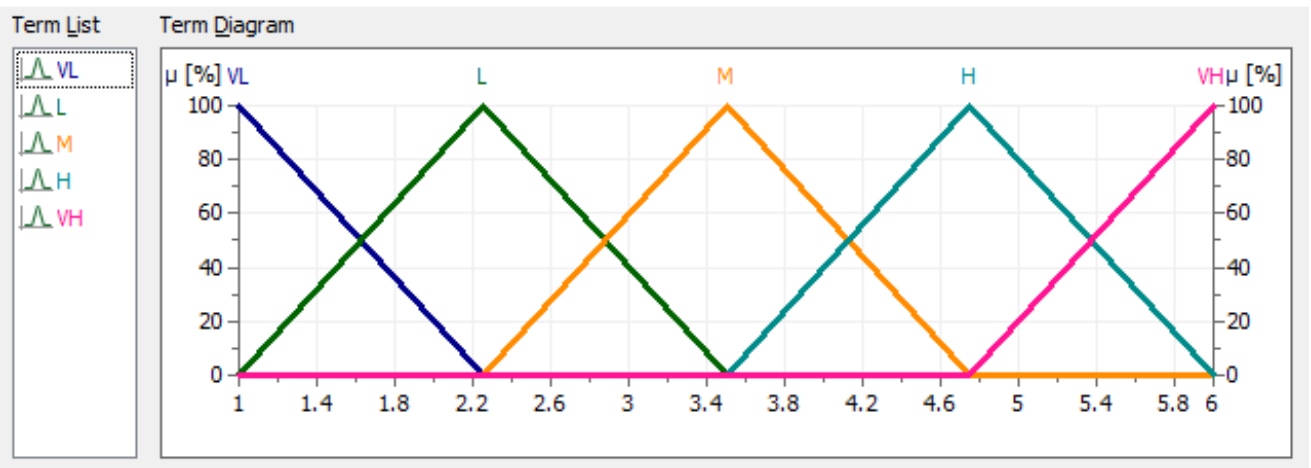

Figure 5. Linguistic variable Species Extinction.

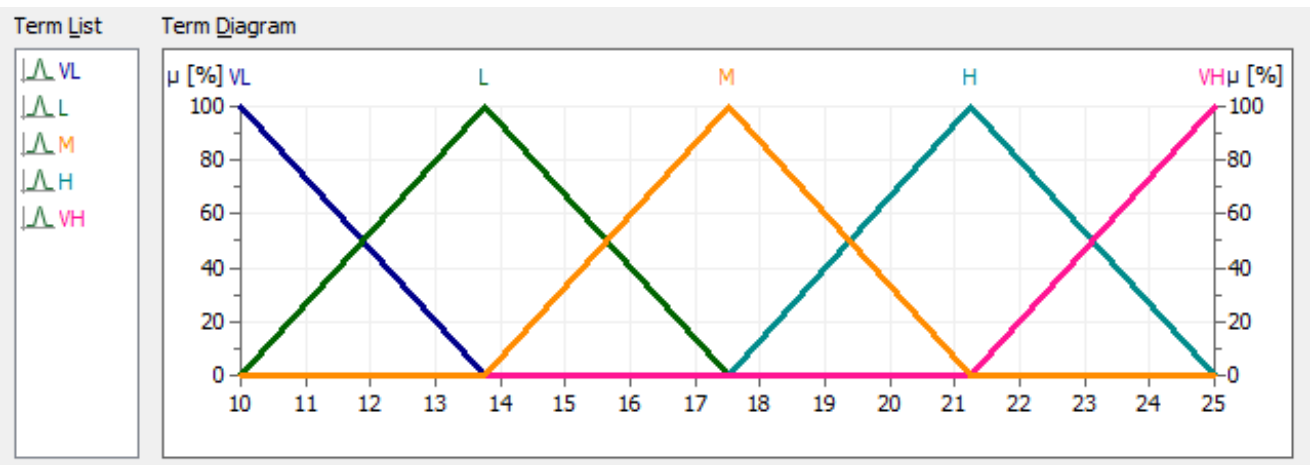

Figure 6. Linguistic Variable Spread of Diseases.

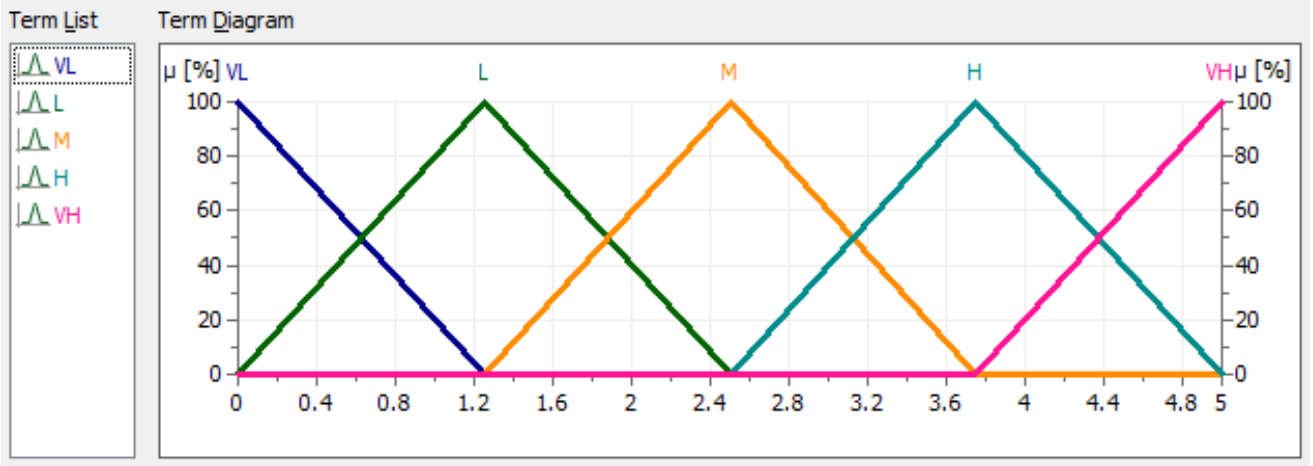

Figure 7. Linguistic Variable Deforestation.

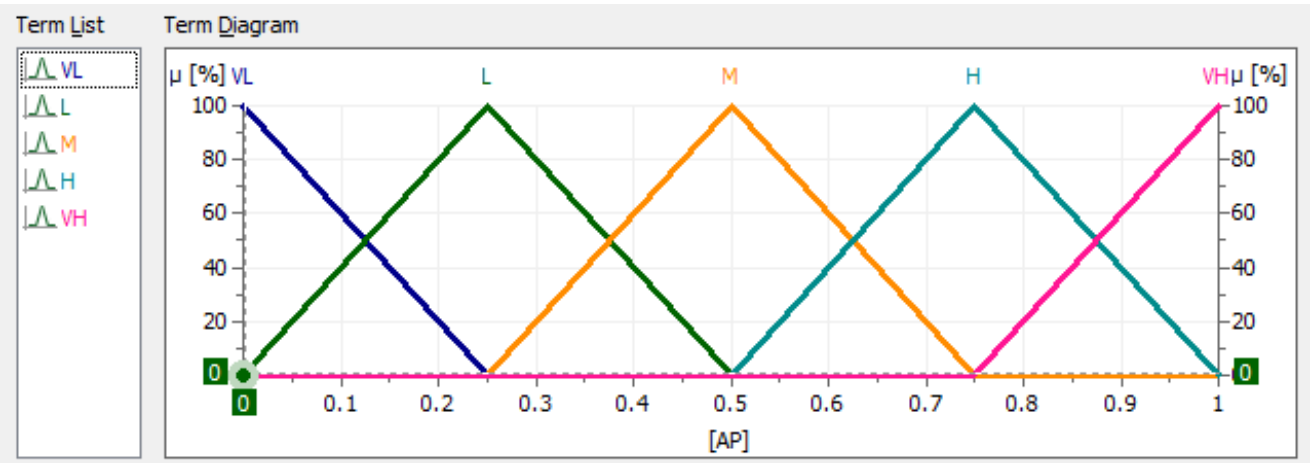

Figure 8. Linguistic Variable of Agricultural Productivity.

\subsubsection{Input Output Variables Domain Determination}

The input and output variables domains are shown in table 3. Parameters of the linguistic variables of fuzzy number for different input and output variables are shown in the Figures 1-8. Parameters of linguistic terms are adjusted from [10] and historical temperature and rainfall records of Bangladesh Meteorological Department. 
Table 3. Variables of Group Inputs.

\begin{tabular}{lllll}
\hline Variable Name & Type & Domain & Unit & Default \\
\hline Input & & & & \\
Temperature (Temp) & $\times \times$ & {$[5,35]$} & Celsius & 18 \\
Weather Disasters (WD) & $\times \times$ & {$[20,50]$} & $\%$ & 25 \\
Water Availability (WA) & $\times \times$ & $\%$ & $\%$ & 2.5 \\
Monsoon Level (ML) & $\times \times$ & {$[200,1800]$} & $\mathrm{mm}$ & 300 \\
Species Extinction (SE) & $\times \times$ & {$[1,6]$} & $\%$ & 2.5 \\
Spread of Diseases (SD) & $\times \times$ & $010,25]$ & $\%$ & 17.5 \\
Deforestation (DF) & $\times \times$ & $0,5]$ & $\%$ & 2.5 \\
Output & & & \\
Agricultural Productivity (AP) & $\times \times$ & $0,100]$ & $\%$ & 25 \\
\hline
\end{tabular}

\subsection{Fuzzy Rule Block Formulations}

Rule blocks contain the control strategy of a FES where each rule block confines all rules for the same context. A context is defined by the same input and output variables of the rules. A rule consists of 'if-then' parts the 'if' part describes the situation, for which the rules are designed and the 'then' part describes the response of the fuzzy system in this situation. The processing of the rules starts with calculating the 'if' part. Then, MAX-MIN method is used to operate the rule block. The fuzzy composition combines different rules to obtain one conclusion. Here, we see that there are 7 inputs of linguistic variables and each variable consist with 5 membership function, so $5^{7}=78125$ rules can be generated from the system [19]. Table 4 illustrates some composition of Temp and WD.
Table 4. Fuzzy rules block of AP to (Temp, WD).

\begin{tabular}{llllllll}
\hline Rules Block & \multicolumn{7}{c}{ Temperature } \\
\hline$\#$ & & & & M & H & VH & L \\
R1 & VL & VL & L & M & H & VH & M \\
R2 & L & L & L & M & H & VH & H \\
R3 & M & M & M & M & H & VH & L \\
R4 & H & H & H & H & H & VH & VL \\
R5 & VH & VH & VH & VH & VH & VH & VH \\
\hline
\end{tabular}

Rules block of fuzzy reasoning for the impacts of Temp, which is WD to AP is shown in Table 4. In Table 5 few fuzzy rules are displayed. Similarly 5 more rule blocks are formulated.

\section{Results and Discussions}

This section presents the results obtained from the proposed inference system and discussed the proposed system with others works.

\subsection{Results}

In this section inferences on agricultural production have been made based on different inputs. A set of fuzzy rules have been applied to get inference of agriculture production (AP) on different linguistic terms in the form of $\mathrm{f}($ Temp, WD, WA, ML, SE, SD, DF) $\rightarrow$ AP.

Table 5. Fuzzy rules block to measure AP with seven linguistic variables.

\begin{tabular}{|c|c|c|c|c|c|c|c|c|c|c|}
\hline \multicolumn{2}{|c|}{ Rules Block } & & \multirow{2}{*}{$\begin{array}{l}1 \\
\text { Temp }\end{array}$} & \multirow{2}{*}{$\begin{array}{l}2 \\
\text { WD }\end{array}$} & \multirow{2}{*}{$\begin{array}{l}3 \\
\text { WA }\end{array}$} & \multirow{2}{*}{$\begin{array}{l}4 \\
\mathrm{ML}\end{array}$} & \multirow{2}{*}{$\begin{array}{l}5 \\
\text { SE }\end{array}$} & \multirow{2}{*}{$\begin{array}{l}6 \\
\text { SD }\end{array}$} & \multirow{2}{*}{$\begin{array}{l}7 \\
\text { DF } \\
\end{array}$} & \multirow{2}{*}{$\begin{array}{l}\text { Output } \\
\text { AP }\end{array}$} \\
\hline \multirow{2}{*}{ \# } & \multirow{2}{*}{$\mathbf{R}_{\mathbf{i}}$} & Variables & & & & & & & & \\
\hline & & Terms & [vl,l,m,h,vh] & [vl,l,m,h,vh] & [vl,l,m,h,vh] & [vl,l,m,h,vh] & [vl,l,m,h,vh] & [vl,l,m,h,vh] & [vl,l,m,h,vh] & [vl,l,m,h,vh] \\
\hline 1 & $\mathrm{R}_{1}$ & Temp [vl,l,m,h,vh] & $\mathrm{M}$ & $\mathrm{V1}$ & $\mathrm{M}$ & $\mathrm{L}$ & $\mathrm{Vl}$ & $\mathrm{L}$ & $\mathrm{L}$ & $\mathrm{H}$ \\
\hline 2 & $\mathrm{R}_{2}$ & $\mathrm{WD}[\mathrm{vl}, \mathrm{l}, \mathrm{m}, \mathrm{h}, \mathrm{vh}]$ & $\mathrm{H}$ & VL & $\mathrm{L}$ & M & $\mathrm{H}$ & $\mathrm{L}$ & $\mathrm{L}$ & $\mathrm{VH}$ \\
\hline 3 & $\mathrm{R}_{3}$ & $\mathrm{WA}[\mathrm{vl}, \mathrm{l}, \mathrm{m}, \mathrm{h}, \mathrm{vh}]$ & $\mathrm{H}$ & $\mathrm{H}$ & $\mathrm{H}$ & $\mathrm{H}$ & $\mathrm{L}$ & $\mathrm{L}$ & $\mathrm{L}$ & $\mathrm{L}$ \\
\hline 4 & $\mathrm{R}_{4}$ & $\mathrm{ML}[\mathrm{vl}, 1, \mathrm{~m}, \mathrm{~h}, \mathrm{vh}]$ & $\mathrm{L}$ & $\mathrm{H}$ & M & M & M & M & M & M \\
\hline 5 & $\mathrm{R}_{5}$ & $\mathrm{SE}[\mathrm{vl}, \mathrm{l}, \mathrm{m}, \mathrm{h}, \mathrm{vh}]$ & M & $\mathrm{H}$ & M & $\mathrm{L}$ & $\mathrm{H}$ & M & $\mathrm{L}$ & M \\
\hline 7 & $\mathrm{R}_{7}$ & $\mathrm{DF}[\mathrm{vl}, \mathrm{l}, \mathrm{m}, \mathrm{h}, \mathrm{vh}]$ & VL & $\mathrm{VH}$ & VL & $\mathrm{L}$ & $\mathrm{L}$ & $\mathrm{L}$ & M & VL \\
\hline
\end{tabular}

Table 6. Output (AP) obtained in different cases of inputs.

\begin{tabular}{|c|c|c|c|c|c|c|c|c|}
\hline Rules & 1 & 2 & 3 & 4 & 5 & 6 & 7 & Output \\
\hline Variable Name & Temp & WD & WA & ML & SE & SD & DF & $\mathbf{A P}$ \\
\hline Input Range & {$[5,35]$} & {$[20 \%, 50 \%]$} & {$[2 \%, 7 \%]$} & {$[200,1800]$} & {$[1 \%, 6 \%]$} & {$[10 \%, 25 \%]$} & {$[0.2 \%, 1.5 \%]$} & {$[0,1]$} \\
\hline Cases & {$[\mathrm{vl}, \mathrm{l}, \mathrm{m}, \mathrm{h}, \mathrm{vh}]$} & {$[\mathrm{vl}, \mathrm{l}, \mathrm{m}, \mathrm{h}, \mathrm{vh}]$} & {$[\mathrm{vl}, \mathrm{l}, \mathrm{m}, \mathrm{h}, \mathrm{vh}]$} & {$[\mathrm{vl}, \mathrm{l}, \mathrm{m}, \mathrm{h}, \mathrm{vh}]$} & {$[\mathbf{v l}, \mathbf{l}, \mathbf{m}, \mathbf{h}, \mathbf{v h}]$} & {$[\mathrm{vl}, \mathrm{l}, \mathrm{m}, \mathrm{h}, \mathrm{vh}]$} & {$[\mathbf{v l}, \mathbf{l}, \mathbf{m}, \mathbf{h}, \mathbf{v h}]$} & {$[\mathrm{vl}, \mathbf{l}, \mathbf{m}, \mathbf{h}, \mathrm{vh}]$} \\
\hline Case 1 & 28 & 25 & 2 & 250 & 1 & 10 & 0.2 & 0.40 \\
\hline Case 2 & 32 & 35 & 3 & 300 & 2 & 13 & 0.4 & 0.25 \\
\hline Case 3 & 20 & 20 & 4 & 200 & 3 & 15 & 0.6 & 0.52 \\
\hline Case 4 & 15 & 40 & 5 & 800 & 4 & 17 & 0.8 & 0.48 \\
\hline Case 6 & 25 & 45 & 7 & 400 & 6 & 22 & 1.3 & 0.55 \\
\hline Case 7 & 34 & 27 & 4.5 & 380 & 3.5 & 25 & 1.5 & 0.40 \\
\hline
\end{tabular}

A rule block consists of 7 rules that have been design with different combination of linguistic terms shown in the Table 5. Agriculture productivities corresponding to real values of linguistic terms are shown in Table 6. The Table 6 depicts that input sets taken in Cases 3, 5 and 6 measures more than $50 \%$ of the agricultural production. Nevertheless, Cases 1 and 7 measures $40 \%$ and Case 2 measure the lowest value that is $25 \%$ of the agriculture production.

Figure 9 shows that aggregated output generated form 7 rules is found to be $75 \%$ where input was taken by Temp=22.4, $\mathrm{WD}=35, \mathrm{WA}=5.15, \mathrm{ML}=1160, \mathrm{SE}=3.35$, $\mathrm{SD}=15.7$ and $\mathrm{DF}=0.59$. In the structure of the fuzzy rule base system it was seen that there were 7 variables and each variables consists 5 membership functions so $5^{7}=$ 
78125 rules could be formed. In Figure 10 it was observed that $6.2 \%$ agriculture production was generated from 78125 rules. The inference made resulted from a large number of rules is computationally difficult, requires huge time and computer memory.

Reasoning of temperature to WD, WA, ML, SD, SE, and DF are shown in the Figure 10 and it illustrates 3D-views of agriculture production in terms of temperature and other input variables. The 3D Figures 11-16 illustrated the output $\mathrm{AP}=60.72 \%$ while considering the inputs as $\mathrm{Temp}=19$, $\mathrm{DF}=1.4 \%, \mathrm{ML}=478, \mathrm{SD}=12 \%, \mathrm{SE}=1.2 \%, \mathrm{WA}=3.9$, and $\mathrm{WD}=27$.

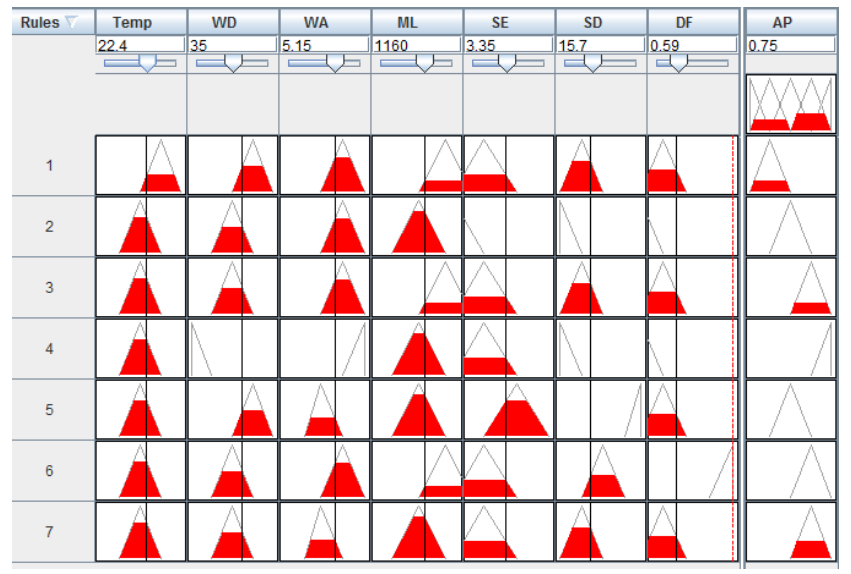

Figure 9. Fuzzy Inference Outputs from 7 rules.

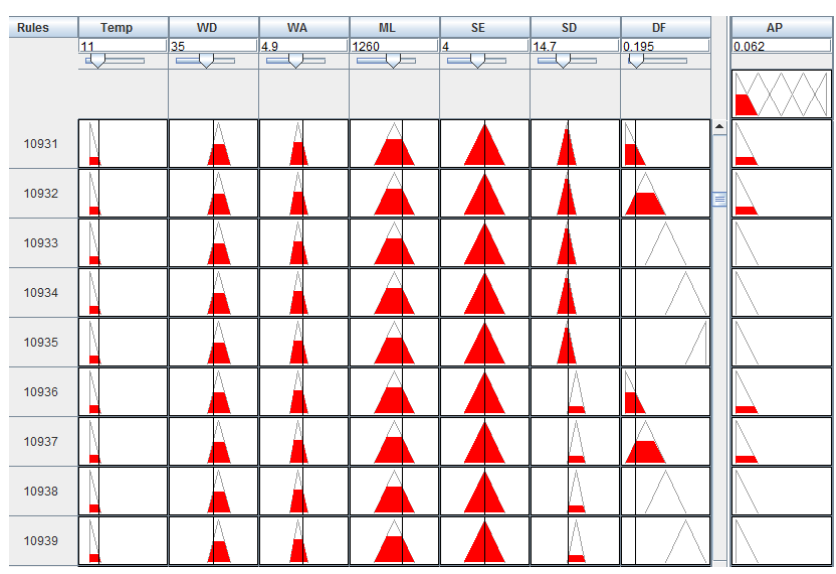

Figure 10. Fuzzy Inference Outputs from 78125 rules.

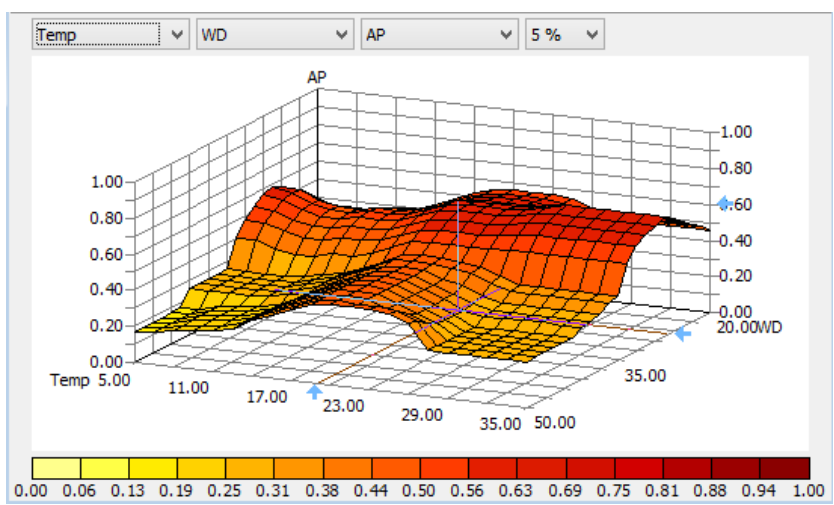

Figure 11. 3D-Fuzzy Reasoning of Variable Temp.
Fuzzy reasoning of temperature to WD, WA, ML, SD, SE, and DF are shown in Figures 11-16. The 3D-figures are produced by using fuzzy TECH software while taking the following inputs where Temp $=19, \mathrm{DF}=1.4 \%, \mathrm{ML}=478$, $\mathrm{SD}=12 \%, \mathrm{SE}=1.2 \%, \mathrm{WA}=3.9, \mathrm{WD}=27$, and $\mathrm{AP}=60.72 \%$.

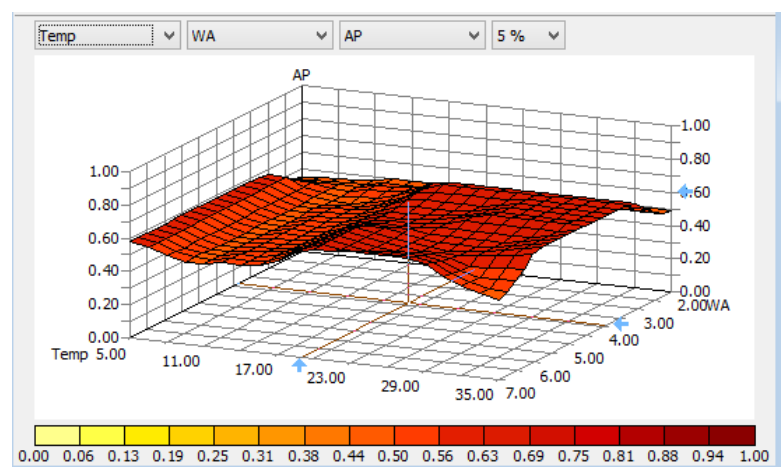

Figure 12. 3D- Fuzzy Reasoning of Variable WA.

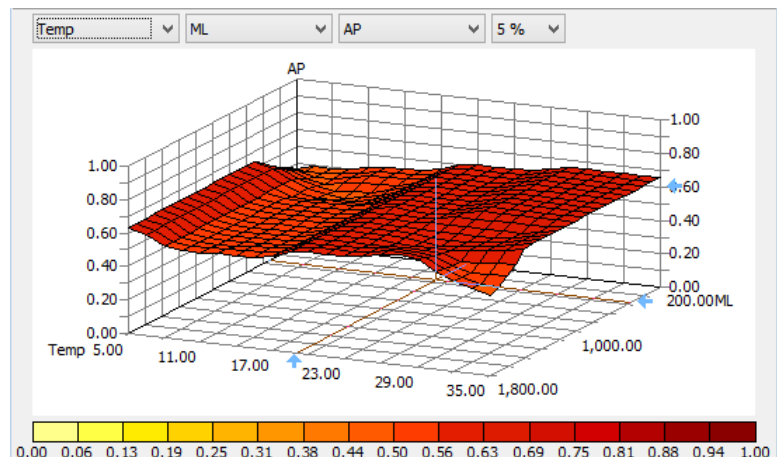

Figure 13. 3D-Fuzzy Reasoning of Variable AP.

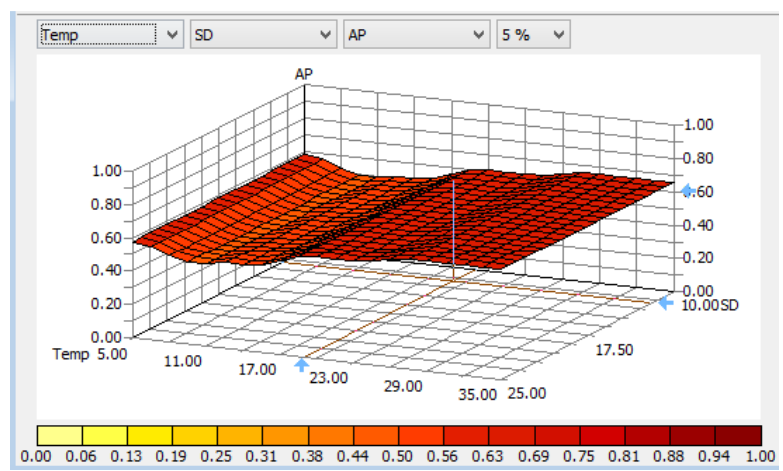

Figure 14. 3D- Fuzzy Reasoning of Variable SD.

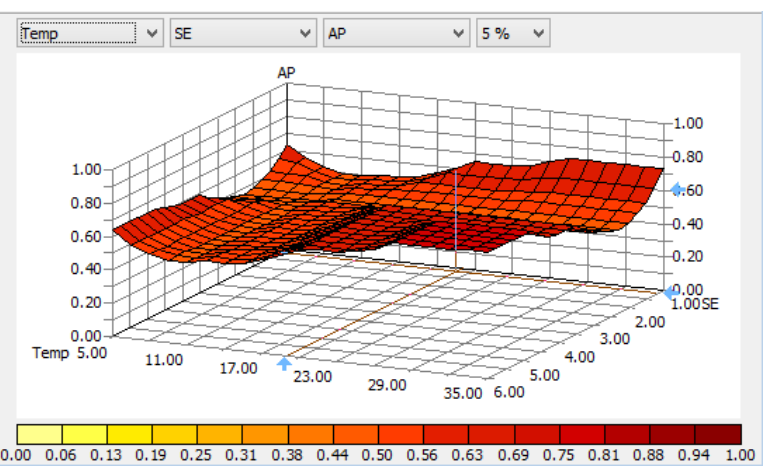

Figure 15. 3D- Fuzzy Reasoning of Variable SE. 


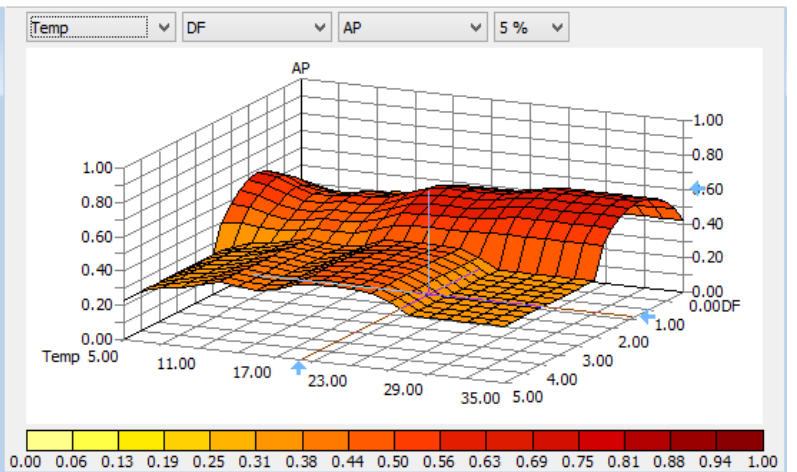

Figure 16. 3D-Fuzzy Reasoning of Variable DF.

Three dimensional surface views of effects of temperature and other five factors to agricultural productions are depicted in Figures 11-16. In Figure 11, it was seen that "f(Temp, WD) $\rightarrow$ AP" the variants of temperature and weather disaster to agricultural production. It was observed that as temperature and weather disaster increases to its maximum level the agriculture production reduces to minimum level. In addition, when temperature is around 23 and the weather disaster is below 20 , the agriculture production reaches $60 \%$. Further, in Figure 12 depicted the output of the function " $\mathrm{f}(\mathrm{Temp}$, WA) $\rightarrow$ AP" that temperature and water availability have a homogeneous effect on agriculture production. This indicates that the effects of increased temperature are balanced by the supply of available water. The Figure 13 depicted the output of the function " $\mathrm{f}(\mathrm{Temp}, \mathrm{ML}) \rightarrow \mathrm{AP}$ " represent the effects of temperature and monsoon level to agriculture production. Monsoon level indicates the precipitation in a region. High precipitation damages agricultural production. Monsoon level below 400 and temperature between the ranges 19 to 23 provides $60 \%$ of agriculture production.

Effects of temperature and spread of diseases to agriculture production is shown in Figure 14 with " $\mathrm{f}(\mathrm{Temp}, \mathrm{SD}) \rightarrow \mathrm{AP}$." It was found that the minimum spread of diseases can produce more than $55 \%$ agriculture production while temperature remains in the range of 19 to 32 . In Figure 15 depicted the output of the function "f(Temp, SE) $\rightarrow$ AP" depicted that species extinction has a long term effect on production. At a high level of species extinction level above 3.5 and temperature below $11^{\circ} \mathrm{C}$ produces below $40 \%$ agriculture production. On the other hand while temperate remains in the range of 23 to 32 and species extinction remains below 2.5 the agriculture production found to be more than $60 \%$. In Figure 16 depicted the output of the function "f(Temp, DF $) \rightarrow \mathrm{AP}$ " represent that deforestation has an immediate effect on agriculture production. This shows that agriculture production is below $20 \%$ when the deforestation is above 1 and temperature in the range of 23 to 29 . Also, it was found that the agriculture production is above $40 \%$ while deforestation remains below 0.5 and temperature remains in the range of 23 to 29 .

\subsection{Discussions}

Impact due to climate change on agriculture production results an effect of food security [3]. Climate change (effects on sea level rise, temperature, rainfall, flood cyclone, water salinity, soil salinity, land erosion siltation, drought and diseases) leads to agriculture production (in the ways of declining land, plant diseases, decrease soil fertility, hamper of seasonal yield and damage in production) [3]. The present study tries to infer the agricultural productivity on different arrangement of climate factors considered. Fuzzy logic system developed in [4] for identification of plant diseases is found to a better decision making tool for plant disease management. NFS system proposed in [5] to infer the production of potato and analyse impact of rainfall, humidity and temperature in potato yield. In this study, the investigators believe that proposed NFS system will help farmers for taking decision of selecting right crop. Comparing with the method proposed in [5] the present study takes input of five atmospheric and climate terms such as temperature, water availability and monsoon level, deforestation, species extinction and spread of diseases to estimate the percentage of agricultural production. The proposed method generated surface view of six factors shown in Figures 11-16 that indicates how agriculture production is implied by the stated factors. A disease diagnosis method is developed by using fuzzy logic system [6] that is able to determine the severity of crop disease on the basis of existing humidity, temperature, light and wind. A fuzzy logic system has been developed [7] to select land for specific crops. The system takes inputs of soil "organic content, depth, $\mathrm{pH}$, water soil surface texture" and provides outputs of optimal criteria of land profile. The "Adaptive Neuro FIS" developed in [8] which is able to forecast seasonal rice yield where the system takes inputs regional meteorological data. FES proposed in [10] which is used for analysing the impact of climate change in Indian agriculture production and the system has been verified with expert individual. In the present study of FES, we generated agriculture production by taking six inputs as proposed in [10] and found that the output generated form the rule based system inclined to expert knowledge.

\section{Conclusions}

The study reviewed the effects of climate change by using fuzzy logic system on agricultural productivity in Bangladesh. It was found that the adverse change of some factors in climate impacts on agricultural productivity. On expert perception change of climates has long term impacts on agriculture. Agricultural products depends on many factors however the study shows output for the various changes in seven input variables. Combinations of climate variables like Temp, WD, WA, ML, SD, SE and DE are considered as fuzzy linguistic variables generated through sets different of fuzzy rules and applied to get agriculture production output. It was observed that moderate Temp with pure WA resulted from moderate ML produces medium agriculture production whereas $\mathrm{WD}, \mathrm{DE}, \mathrm{SD}$ damage and reduce the agricultural production rate.

The study demonstrates the application of fuzzy logic to examine the impact of climate change on the Agriculture in 
Bangladesh. The parameters of linguistic variables applied in the present FIS have found some ambiguity and the ambiguity varies among expert to expert. However once an inference system is developed, parameters and different rules of rule black can be redesigned on the consultation on expert individuals and historical records of temperature; monsoon level, water availability. Based on historical data fuzzy logic system was used to get the productivity output of specific crops in any specific area of a country.

\section{References}

[1] L. A. Zadeh, (1965), Information and control. Fuzzy sets, vol. 8, pp. 338-353.

[2] L. A. Zadeh, (1975). Fuzzy logic and approximate reasoning. Synthese, vol. 30, pp. 407-428.

[3] M. Hossain and A. Majumder, (2018). Impact of climate change on agricultural production and food security: A review on coastal regions of Bangladesh. International Journal of Agricultural Research, Innovation and Technology, vol. 8, pp. 62-69.

[4] S. S. Sannakki and V. S. Rajpurohit, "(2011). A Survey on Applications of Fuzzy Logic in Agriculture 1.

[5] F. Jawad, T. U. R. Choudhury, S. A. Sazed, S. Yasmin, K. I. Rishva, F. Tamanna, et al., (2016). Analysis of optimum crop cultivation using fuzzy system. IEEE/ACIS 15th International Conference on Computer \& Information Science (ICIS), pp. 1-6.

[6] P. Pandey, R. Litoriya, and A. Tiwari, (2018). A framework for fuzzy modelling in agricultural diagnostics, Journal Européen des Systèmes Automatisés, vol. 51, p. 203.

[7] Y. Liu, L. Jiao, Y. Liu, and J. He, (2013). A self-adapting fuzzy inference system for the evaluation of agricultural land, Environmental modelling \& software, vol. 40, pp. 226-234.

[8] P. Kumar, (2011). Crop yield forecasting by adaptive neuro fuzzy inference system, Mathematical Theory and Modeling, vol. 1, pp. 1-7.

[9] N. Alavi, (2013). Quality determination of Mozafati dates using Mamdani fuzzy inference system. Journal of the Saudi society of agricultural sciences, vol. 12, pp. 137-142.

[10] S. Karthika, N. Punithavelanb, S. K. Dasha, and A. Felixa, (2018). Fuzzy Expert system for the Impact of Climate Change in Indian Agriculture, International Journal of Pure and Applied Mathematics, vol. 118, pp. 455-473.

[11] T. Rajaram and A. Das, (2010). Modeling of interactions among sustainability components of an agro-ecosystem using local knowledge through cognitive mapping and fuzzy inference system. Expert Systems with Applications, vol. 37, pp. 1734-1744.

[12] K. Liu, H. Liang, K. Yeh, and C. Chen, (2009). A qualitative decision support for environmental impact assessment using fuzzy logic, Journal of Environmental Informatics, vol. 13.

[13] S. Yelapure and R. Kulkarni, (2012). Literature review on expert system in agriculture, International Journal of Computer Science and Information Technologies, vol. 3, pp. 5086-5089.
[14] S. Dubey, R. Pandey, and S. Gautam, (2013). Literature review on fuzzy expert system in agriculture, International Journal of Soft Computing and Engineering, vol. 2, pp. 289-291.

[15] S. Guillaume and B. Charnomordic, (2012). Fuzzy inference systems: An integrated modeling environment for collaboration between expert knowledge and data using FisPro, Expert Systems with Applications, vol. 39, pp. 8744-8755.

[16] X. Zhang and X. Cai, (2011). Climate change impacts on global agricultural land availability, Environmental Research Letters, vol. 6, p. 014014.

[17] G. J. Klir, U. St. Clair, and B. Yuan, (1997). Fuzzy set theory: foundations and applications: Prentice-Hall, Inc.

[18] L. A. Zadeh, G. J. Klir, and B. Yuan, (1996). Fuzzy sets, fuzzy logic, and fuzzy systems: selected papers, vol. 6: World Scientific.

[19] O. Castillo, P. Melin, J. Kacprzyk, and W. Pedrycz, (2007). Type-2 fuzzy logic: theory and applications, IEEE International Conference on Granular Computing (GRC 2007), pp. 145-145.

[20] R. Fullér and H.-J. Zimmermann, (1993). On Zadeh's compositional rule of inference, Fuzzy Logic, ed: Springer, pp. 193-200.

[21] R. Fullér and B. Werners, (1992). The compositional rule of inference with several relations, Tatra Mountains Mathematical Publications, vol. 1, pp. 39-44.

[22] H. R. Berenji, (1992). Fuzzy logic controllers, An introduction to fuzzy logic applications in intelligent systems, ed: Springer, pp. 69-96.

[23] T. S. Ledley, E. T. Sundquist, S. E. Schwartz, D. K. Hall, J. D. Fellows, and T. L. Killeen, (1999). Climate change and greenhouse gases," Eos, Transactions American Geophysical Union, vol. 80, pp. 453-458.

[24] S. Mohanty, R. Wassmann, A. Nelson, P. Moya, and S. Jagadish, (2013). Rice and climate change: significance for food security and vulnerability, International Rice Research Institute, vol. 14, pp. 1-14.

[25] S. Rahman and A. R. Anik, (2020). Productivity and efficiency impact of climate change and agroecology on Bangladesh agriculture, Land Use Policy, vol. 94, p. 104507.

[26] W. Page. (2017). A student's guide to Global Climate Change. Available:

https://archive.epa.gov/climatechange/kids/impacts/signs/temp erature.html\#: :text=Warmer\%20temperatures\%20can\%20als o\%20lead,and $\% 20$ the $\% 20$ environment $\% 20$ will $\% 20$ be.

[27] C. Zhao, B. Liu, S. Piao, X. Wang, D. B. Lobell, Y. Huang, et al., (2017). Temperature increase reduces global yields of major crops in four independent estimates, Proceedings of the National Academy of Sciences, vol. 114, pp. 9326-9331.

[28] V. P. Alan Buis. (2019). A Degree of Concern: Why Global Temperatures Matter (June ed.). Available: https://climate.nasa.gov/news/2865/a-degree-of-concern-whyglobal-temperatures-matter/

[29] M. Dell, B. F. Jones, and B. A. Olken, (2012). Temperature shocks and economic growth: Evidence from the last half century, American Economic Journal: Macroeconomics, vol. 4, pp. 66-95. 
[30] M. Garschagen, M. Hagenlocher, M. Comes, M. Dubbert, R. Sabelfeld, Y. J. Lee, et al., (2016). World Risk Report 2016.

[31] M. Shamsuddoha and R. K. Chowdhury, (2007). Climate change impact and disaster vulnerabilities in the coastal areas of Bangladesh, COAST Trust, Dhaka, pp. 40-48.

[32] J. K. Basak, R. A. M. Titumir, and N. C. Dey, (2013). Climate change in Bangladesh: a historical analysis of temperature and rainfall data, Journal of Environment, vol. 2, pp. 41-46.

[33] R. Mahmood, D. R. Legates, and M. Meo, (2004). The role of soil water availability in potential rainfed rice productivity in Bangladesh: applications of the CERES-Rice model, Applied Geography, vol. 24, pp. 139-159.

[34] J. Kirby, M. Mainuddin, F. Mpelasoka, M. Ahmad, W. Palash, M. Quadir, et al., (2016). The impact of climate change on regional water balances in Bangladesh, Climatic change, vol. 135 , pp. 481-491.

[35] C. Román-Palacios and J. J. Wiens, (2020). Recent responses to climate change reveal the drivers of species extinction and survival, Proceedings of the National Academy of Sciences, vol. 117, pp. 4211-4217.

[36] D. E Shehvaar, W. Idris, and M. Ahmed, (2020). "Climate Change and the Surge for Pandemics," Journal of Sustainable Development, vol. 13.

[37] M. Zeraatpisheh, E. Bakhshandeh, M. Hosseini, and S. M. Alavi, (2020). Assessing the effects of deforestation and intensive agriculture on the soil quality through digital soil mapping," Geoderma, vol. 363, p. 114-139.

[38] B. B. Statistics, (2018). Statistical yearbook of Bangladesh, Statistics Division, Ministry of Planning, Dhaka, Government of the People's Republic of Bangladesh.

[39] M. O. Finance, (2018). Bangladesh Economic Review 2018, ed: Government of Bangladesh.

[40] M. S. Hossain, M. Arshad, L. Qian, H. Kächele, I. Khan, M. D. I. Islam, et al., (2020). Climate change impacts on farmland value in Bangladesh, Ecological Indicators, vol. 112, pp. 106-181. 